\title{
Acid-sensing Ion Channel 2 Expression in the Epithelial Cells of Rat Cerebral Ventricle and Choroid Plexus
}

\author{
Shin Kikuchi ${ }^{{ }^{*}}$, Takafumi Ninomiya ${ }^{1}$, Tomoyuki Kawamata ${ }^{2}$ and Haruyuki Tatsumi ${ }^{1}$ \\ ${ }^{1}$ Department of Anatomy 1, Sapporo Medical University School of Medicine, Sapporo, Japan \\ ${ }^{2}$ Department of Anesthesiology, Wakayama Medical University, Wakayama, Japan
}

"Corresponding author: Shin Kikuchi, Department of Anatomy 1, Sapporo Medical University School of Medicine, South 1 West 17 , Chuo-ku, Sapporo, Hokkaido, 060-8556, Japan, Tel: +81-11-211-6111; Fax: +81-11-640-3002; E-mail: ksin@sapmed.ac.jp

Rec date: Dec 04, 2014, Acc date: Feb 14, 2015, Pub date: Feb 16, 2015

Copyright: $\odot 2015$ Kikuchi S, et al. This is an open-access article distributed under the terms of the Creative Commons Attribution License, which permits unrestricted use, distribution, and reproduction in any medium, provided the original author and source are credited.

\begin{abstract}
Acid-sensing ion channel 2 (ASIC2) works as a proton-gated ion channel. Our previous report showed that ASIC2 was expressed in ciliated and stereociliated cells. In the central nervous system, ASIC2 was detected in neurons. However, ciliated ependymal cells also expressed ASIC2. In addition to ependymal cells in the cerebral ventricle, epithelial cells of the choroid plexus expressed ASIC2. We clarified that ASIC2 localized at the cilia membrane in ciliated ependymal cells and at the epithelial cell body in the choroid plexus, irrespective of ciliation. The role of ASIC2 in the ependymal cells remains to be clarified.
\end{abstract}

Keywords: ASIC2; Ependymal cell; Choroid plexus; Cilia

\section{Introduction}

Acid-sensing ion channels (ASICs) are voltage-independent $\mathrm{Na}^{+}$ channels of the epithelial sodium channel/degenerin (ENaC/DEG) gene family [1] that are activated by external cations [2,3]. Six different ASIC subunits have been identified in mammals, encoded by four $A S I C$ genes (ASIC1-4). Acid-sensing ion channel (ASIC) 1 and ASIC2 each have alternative splice variants; ASIC1a and ASIC1b; ASIC2a and ASIC2b, respectively [4-6]. ASICs have the common structures; two hydrophobic transmembrane segments (M1 and M2) and extracellular cysteine-rich domains between M1 and M2 [3,7]. Acid-sensing ion channels generate either homo- or hetero-trimers [8], and are widely expressed in both neuronal [9-11] and non-neuronal organs [12-15].

Among ASICs, ASIC2 subtype homomeric channels demonstrate unique functions. The $A S I C 2$ gene was originally cloned as brain sodium channel 1 (BNaC1) [10]. Compared with the other ASIC homomeric channels, ASIC2a homomeric channels require the lowest $\mathrm{pH},(\mathrm{pH}<5.0)$ to be activated. The other ASIC2 subtype, ASIC2b, does not assemble into a functional channel by itself. The ASIC2 subtypes generate homo- or heteromeric channels with other ASICs and contribute perform unique functions, in the mammal nervous system [16-20].

Previously, we showed that ASIC2 expression in rats was detected in cilia membranes of ciliated cells and in the cell body of cells having stereo-cilia [21,22]. ASIC2 expression in the ciliated cells was limited to the cilia membrane in the rat respiratory system and oviduct [21]. Its expression was detected in mature cilia, not in immature or primary cilia, and was observed in the development of the olfactory epithelium [22]. Recently, Vina et al. showed that ASIC2 was expressed in cilia of non-sensory olfactory cells in zebrafish [23].

In the nervous system, ependymal cells are ciliated. Representative ependymal cells are histologically observed in the ventricular wall and central canal in the brain and spinal cord, respectively. In the brain ventricle, the choroid plexus is also observed and the surface of the choroid plexus comprise modified ependymal cells.

In the present study, we demonstrated the presence of ASIC2 in ependymal cells and choroid plexus in adult rat brain and spinal cord. This is the first report showing that ASIC2 is expressed in the central nervous system (CNS), except in the neurons.

\section{Materials and Methods}

\section{Immunohistochemistry}

All animal experiments conformed to the regulations of the Sapporo Medical University Animal Care Committee and were conducted in accordance with the National Institute of Health guidelines on animal care. All efforts were made to minimize the number of animals used and their suffering. Following cardiac perfusion of $4 \%$ paraformaldehyde dissolved in a $0.01 \mathrm{M}$ phosphatebuffered saline (PBS) ( $\mathrm{pH} 7.4)$ (4\% PFA), the brain and spinal cord were excised from adult Sprague-Dawley (SD) rats under deep anesthesia with sodium pentobarbital ( $50 \mathrm{mg} / \mathrm{kg}$ body weight). The specimens were fixed with the same fixative at $4^{\circ} \mathrm{C}$ overnight. After the specimens were washed and cryoprotected, they were embedded in $\mathrm{NEG}^{\mathrm{TM}}$ (RICHARD-ALLAN Scientific $^{\mathrm{TM}}$, Kalamazoo, MI, USA). Serial sections, each $12 \mu \mathrm{m}$ thick, were cut with a cryostat (HM 5050E, Microm, Heidelberg, Germany) and placed on MAS-coated slides (MATSUNAMI Glass Ind., Ltd., Osaka, Japan).

For the immunohistochemistry, a synthetic peptide (VPLQTALGTLEEIA) with common residues to ASIC2a and ASIC2b was coupled to keyhole limpet hemocyanin (Sigma, St. Louis, MO, USA) and emulsified with Freund's complete adjuvant (DIFCO, Detroit, MI, USA). Guinea pigs were immunized with injections of peptides conjugated to keyhole limpet hemocyanin. The anti-ASIC2 antibody was affinity-purified by passing the purified IgGs through Sepharose columns to which the unconjugated ASIC2 peptide had been immobilized [24]. A previous study confirmed the specificity of the antibody by a pre-absorption test with a suitable antigen $[21,24]$. 
The compound was removed from the specimens. After incubation with $5 \%$ normal goat serum in PBS, the sections were reacted with the anti-ASIC2 antibody at $4^{\circ} \mathrm{C}$ overnight. The reacted specimens were washed five times with PBS containing 0.3\% Triton-X 100 (PBST) and incubated with a biotinylated anti-guinea pig IgG antibody (Jackson ImmunoResearch Labs., Inc., West Grove, PA, USA) for 90 min at room temperature (RT). After the specimens were washed three times with distilled water, they were reacted with streptavidin (Jackson) for 30 min at RT. Immunoreactive sites were visualized using $0.025 \%$ 3,3diamino-benzidine tetrahydrochloride (DAB, Dojin, Kumamoto, Japan) in $0.05 \mathrm{M}$ Tris- $\mathrm{HCl}$ buffer ( $\mathrm{pH} 7.4$ ) containing $0.01 \%$ hydrogen peroxide. Finally, these samples were dehydrated and mounted with MP500 (MATSUNAMI Glass Ind.).

\section{Transmission electron microscopy}

For transmission electron microscopy (TEM), the brain was excised from adult SD rats under deep anesthesia and fixed with 4\% PFA including $0.1 \%$ glutaraldehyde in PBS at $4^{\circ} \mathrm{C}$ overnight. The methods used to mount them were the same for the immunohistochemistry described above. Mounted samples were cut into sections, each $14 \mu \mathrm{m}$ thick, with the cryostat. After each section was removed from the compound and washed in PBS containing 0.1\% Tween 20 (PBSt), it was blocked with 5\% normal goat serum in PBS for $15 \mathrm{~min}$ at RT and incubated with the anti-ASIC2 antibody at $4^{\circ} \mathrm{C}$ overnight. After incubation, each specimen was washed five times with PBSt for $5 \mathrm{~min}$. The samples were incubated with 12-nm anti-guinea pig colloidal gold (Jackson ImmunoResearch Labs., Inc.) at $4^{\circ} \mathrm{C}$ overnight. After each specimen was washed three times with PBS for $5 \mathrm{~min}$, they were fixed with $0.1 \%$ glutaraldehyde in PBS for $10 \mathrm{~min}$ at RT. After the enhanced samples were washed with PBS, they were post-fixed with $2.5 \%$ glutaraldehyde for $90 \mathrm{~min}$ at RT. The samples were dehydrated through a graded ethanol series, embedded in epoxy resin, and cut into ultrathin sections with an ultramicrotome (MT6000, Dupont, Wilmington, DE, USA). The ultrathin sections were then stained with uranyl acetate and lead citrate, and examined with an electron microscope (H7500, HITACHI, Tokyo, Japan).

\section{Results and Disucussion}

The distributions of ASIC2 protein in ependymal cells and choroid plexus were evaluated by immunohistochemistry (Figure 1a-1f). Immunohistochemistry results of rat brain sections performed with antibodies against ASIC2 showed a positive reaction (observed as a brown colors) in the cilia and cytoplasm of the epithelia in the ependymal cells and choroid plexus, respectively (Figure 1a-1d). Similarly, the reaction of ASIC2 antibody was detected in the central canal in the spinal cord (Figure 1e and 1f).

Pre-absorption with the relevant peptide prevented the immunoreaction of ASIC2 (Figure 1g-1i). To clarify the localization of ASIC2 in the cells, we investigated the ultrastructural immunolocalization with TEM. The ependymal cells had a lot of cilia on the apical side and the gold particles were detected on the cilia membranes in the brain ventricles (Figure $2 \mathrm{a}$ and $2 \mathrm{~b}$ ). In the cells of lining the central canal in rat spinal cord, ASIC2 expression was also detected on the cilia membranes (Figure $2 \mathrm{c}$ and $2 \mathrm{~d}$ ). The choroid plexus have not cilia, but instead have microvilli on their surfaces. The gold particles were detected in the bodies of the choroid plexus epithelium (Figure 2e and 2f). The difference in the distribution between the ependymal cells and choroid plexus was in agreement with our previous report [21]. ASIC2 expressions, was observed in the cilia in the ciliated cells of rat trachea or oviduct, and was observed in the cell body in the nonciliated cells of rat inner ear or epididymis [21]. However, unlike the ciliated cells of rat trachea or oviduct, and the nonciliated cells of rat inner ear or epididymis, the ependymal cells and choroid plexus in the brain ventricle share the same space. These results led us to speculate that ASIC2 contributes to maintain the normal functions of cerebrospinal fluid (CSF).

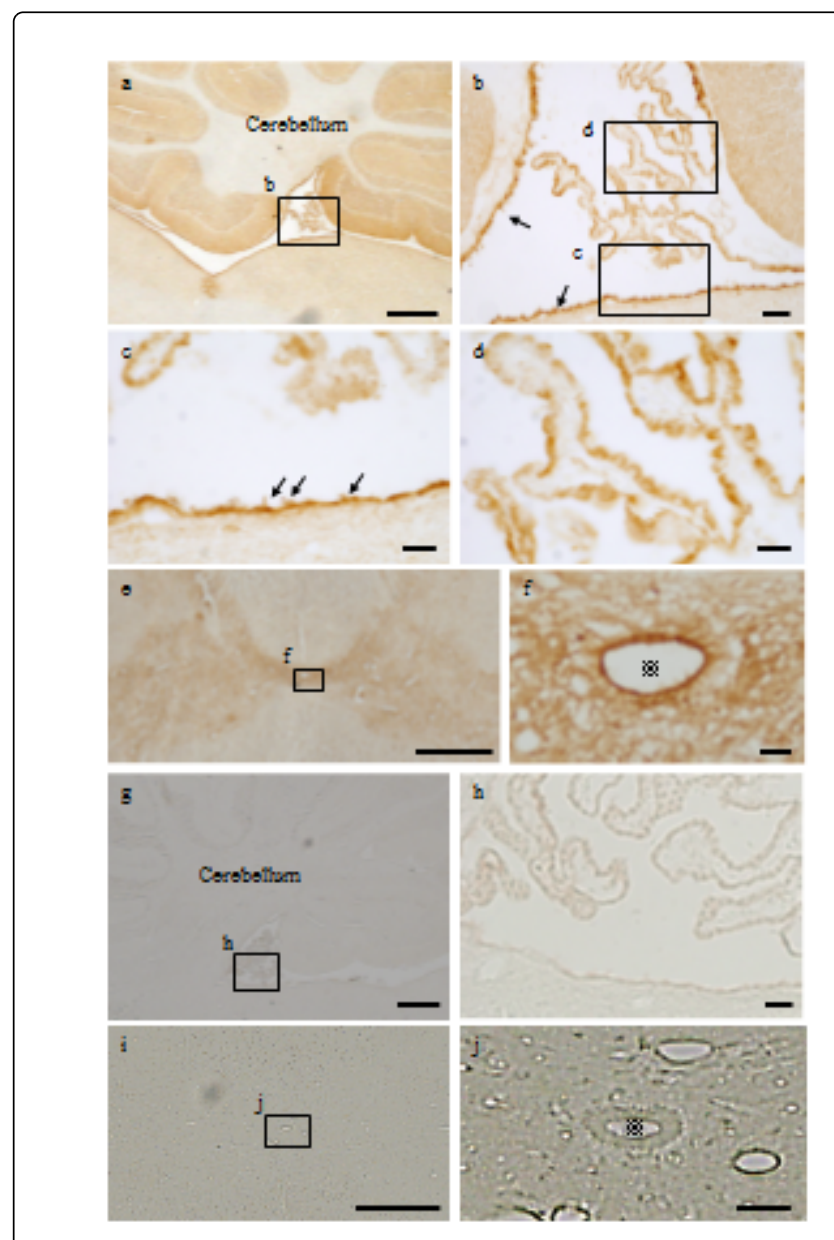

Figure 1: Immunohistochemical localization of ASIC2 in rat brain and spinal cord. In 4th ventricle ( $\mathrm{a}$ and $\mathrm{b}$ ), the immunoreactivities of ASIC2 are detected in ependymal cells (c) and choroid plexus (d). In ependymal cells, the reactions of ASIC2 are detected on cilia (arrows in b and c). In spinal cord (e), the reaction is detected in the marge of central canal ( $※$ in $\mathrm{f}$ ). Results with primary antibody against ASIC2 following preabsorption with the antigen are showed in lower 4 panels; 4 th ventricle ( $g$ and $h$ ) and spinal cord ( $i$ and $j)$. ASIC2 reactions are not detected in ependymal cells, choroid plexus (h) and central canal ( $※$ in j). Bars; $500 \mu \mathrm{m}$ (a, e, g and i), 50 $\mu \mathrm{m}$ (b and $\mathrm{j}$ ) and $20 \mu \mathrm{m}(\mathrm{c}, \mathrm{d}, \mathrm{f}$ and $\mathrm{h})$.

The function of ASIC2 is not well understood [19], however, it has an important role in the nervous system. This has been demonstrated by the fact that behavior analysis of mice with $A S I C 2$ gene disruption showed a decreased defensive response to aversive stimuli, such as predator odors or $\mathrm{CO}_{2}$ inhalation [25]. 


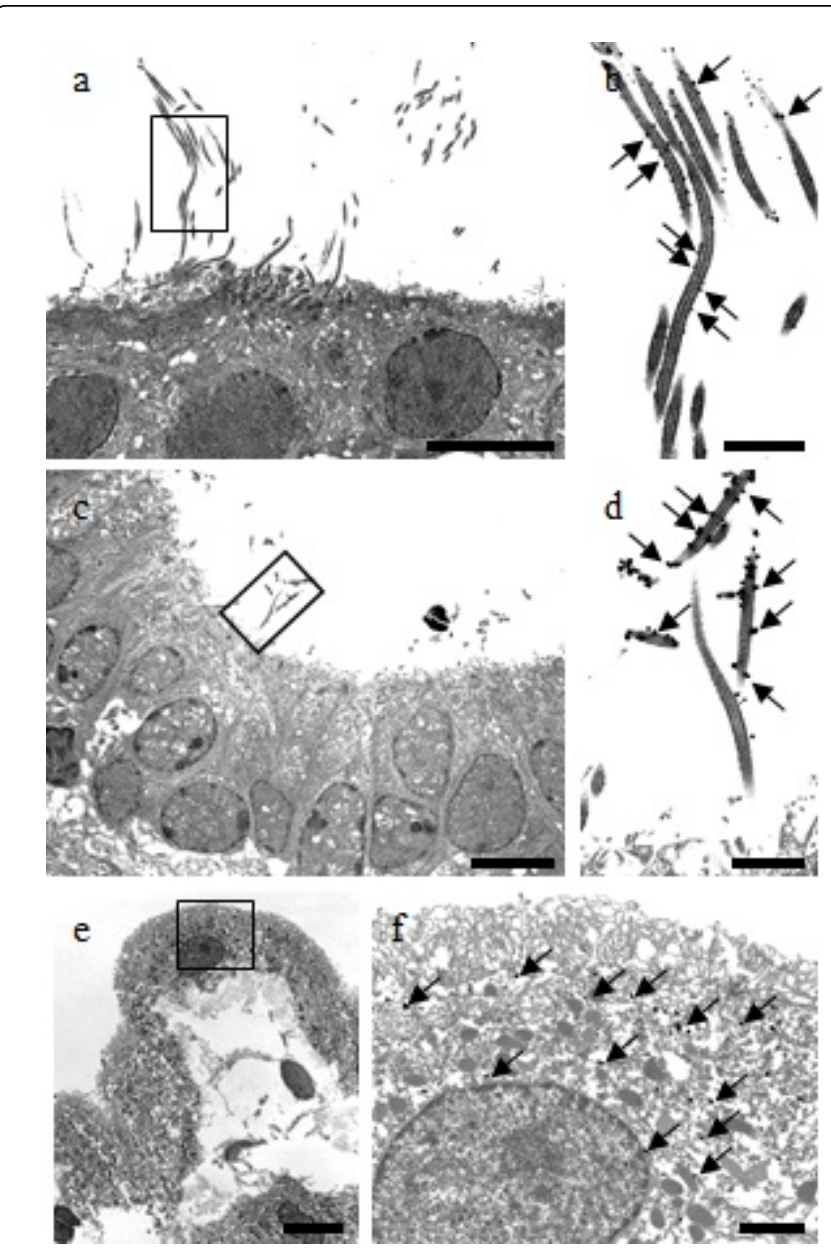

Figure 2: Immunogold electron micrographs showing ASIC2 localization on the rat ependymal cells in brain $(a, b)$ and spinal cord (c, d), and choroid plexus (e, f). The rectangles in a, $c$ and e are shown at higher magnification in $b, d$ and $f$, respectively. ASIC2 immunoreactivity is detected as dots (arrows in $b, d$ and $\mathrm{f}$ ). The reactions are detected on the ciliary membrane in ependymal cells (a-d). ASIC2 expression in choroid plexus is detected in the cell body (e and f). Bars; $10 \mu \mathrm{m}$ (a, c and e) and $2 \mu \mathrm{m}$ (b, $d$ and $\mathrm{f}$ ).

The ependymal cells have cilia that cover the ventricles in the brain and the central canal in the spinal cord, and the choroid plexus projects into the brain ventricles. Therefore, the surface of the ependymal cells and choroid plexus are in contact with CSF. pH of CSF is approximately 7.4 and almost all the fluid is produced by the choroid plexus [26]. The cilia of ependymal cells contribute to the generation of CSF flow and a functional deficiency of the cilia causes CSF accumulation and hydrocephalus $[27,28]$. The beating of the cilia is coordinated by motor proteins [29], gap junctions [30], and hormones [31] to maintain proper CSF circulation.

It is easy to conclude that ASIC2 works as a pH sensor of CSF or a mechanoreceptor to sense CSF fluid in ependymal cells and choroid plexus. However, the in vivo role of ASIC2 as a $\mathrm{pH}$ sensor has remained elusive. The ASIC2a homomultimers require the lowest $\mathrm{pH}$ among ASICs to open the channel $(<\mathrm{pH} 5)[5,16,18]$, and ASIC2b is inactive when expressed alone [5]. This $\mathrm{pH}$ value is far from the physiological range, and ASIC2 homomultimers do not act as a sensor of the reduction of extracellular $\mathrm{pH}$ [32]. On the other hand, the role of ASIC2 as a direct peripheral mechanoreceptor [33] has been controversial for a couple of years [34] because some groups have suggested that ASIC2 does not contribute to mechanosensation [35-37]. Therefore, it is difficult to define the function of ASIC2 as a $\mathrm{pH}$ sensor or mechanoreceptor in the brain or spinal cord.

Harding et al. recently showed that ASIC2 controls another channel, ASIC1a. Furthermore, expression levels at the cell surface in Chinese hamster ovary cells and the expression levels of ASIC2 at synapses are controlled by expression levels of PSD-95, a scaffold protein in the postsynaptic membrane [19]. In addition, Zha et al. reported that the complex of ASIC2 and PSD-95 facilitates the accumulation of ASIC1a into dendritic spines [32]. These groups have suggested a new functional possibility for ASIC2, which may influence other channel expression levels.

The cilia have a lot of membrane receptors [38,39] however, our results could not confirm whether ASIC2 in the ependymal cells and the choroid plexus affects the expression of another channel. Furthermore, the possibility that ASIC2 has other unknown functions remains.

The ASIC2-positive reactions in gray matter in the cerebellum and spinal cord (Figure 11 and 1e) were not nonspecific responses because the results with primary antibody against ASIC2, following preabsorption with the antigen showed that the reactions of the ASIC2 antibody were specific. We did not mention the immune reactions in the gray matter in the cerebellum or the spinal cord in this article. Further experiments are needed in order to clarify the ASIC2 localization in gray matter.

In conclusion, our study showed that ASIC2 was expressed in the cilia and cell bodies of ependymal cells and choroid plexus in rat CNS, respectively, except for neurons. However, the results were not able to clarify the role of ASIC2 in the ependymal cells and choroid plexus in rat CNS. Further investigation into the function of ASIC2 in ependymal cells and choroid plexus is required.

\section{Acknowledgements}

We thank to Ms. E. Suzuki (Sapporo Medical University School of Medicine) for her technical support.

\section{References}

1. Fyfe GK, Quinn A, Canessa CM (1998) Structure and function of the Mec-ENaC family of ion channels. Semin Nephrol 18: 138-151.

2. Chu XP, Papasian CJ, Wang JQ, Xiong ZG (2011) Modulation of acidsensing ion channels: molecular mechanisms and therapeutic potential. Int J Physiol Pathophysiol Pharmacol 3: 288-309.

3. Sherwood TW, Frey EN, Askwith CC (2012) Structure and activity of the acid-sensing ion channels. Am J Physiol Cell Physiol 303: C699-710.

4. Chen CC, England S, Akopian AN, Wood JN (1998) A sensory neuronspecific, proton-gated ion channel. Proc Natl Acad Sci U S A 95: 10240-10245.

5. Lingueglia E, de Weille JR, Bassilana F, Heurteaux C, Sakai H, et al. (1997) A modulatory subunit of acid sensing ion channels in brain and dorsal root ganglion cells. J Biol Chem 272: 29778-29783.

6. Waldmann R, Champigny G, Voilley N, Lauritzen I, Lazdunski M (1996) The mammalian degenerin MDEG, an amiloride-sensitive cation channel activated by mutations causing neurodegeneration in Caenorhabditis elegans. J Biol Chem 271: 10433-10436. 
7. Renard S, Lingueglia E, Voilley N, Lazdunski M, Barbry P (1994) Biochemical analysis of the membrane topology of the amiloridesensitive Na+ channel. J Biol Chem 269: 12981-12986.

8. Jasti J, Furukawa H, Gonzales EB, Gouaux E (2007) Structure of acidsensing ion channel 1 at $1.9 \mathrm{~A}$ resolution and low $\mathrm{pH}$. Nature 449: 316-323.

9. Alvarez de la Rosa D, Zhang P, Shao D, White F, Canessa CM (2002) Functional implications of the localization and activity of acid-sensitive channels in rat peripheral nervous system. Proc Natl Acad Sci USA 99: 2326-2331.

10. Price MP, Snyder PM, Welsh MJ (1996) Cloning and expression of a novel human brain $\mathrm{Na}+$ channel. J Biol Chem 271: 7879-7882.

11. Waldmann R, Champigny G, Bassilana F, Heurteaux C, Lazdunski M (1997) A proton-gated cation channel involved in acid-sensing. Nature 386: 173-177.

12. Cuesta A, Del Valle ME, García-Suárez O, Viña E, Cabo R, et al. (2014) Acid-sensing ion channels in healthy and degenerated human intervertebral disc. Connect Tissue Res 55: 197-204.

13. Jahr H, van Driel M, van Osch GJ, Weinans H, van Leeuwen JP (2005) Identification of acid-sensing ion channels in bone. Biochem Biophys Res Commun 337: 349-354.

14. Shimada S, Ueda T, Ishida Y, Yamamoto T, Ugawa S (2006) Acid-sensing ion channels in taste buds. Arch Histol Cytol 69: 227-231.

15. Ugawa S, Minami Y, Guo W, Saishin Y, Takatsuji K, et al. (1998) Receptor that leaves a sour taste in the mouth. Nature 395: 555-556.

16. Babinski K, Catarsi S, Biagini G, Séguéla P (2000) Mammalian ASIC2a and ASIC3 subunits co-assemble into heteromeric proton-gated channels sensitive to Gd3+. J Biol Chem 275: 28519-28525.

17. Bassilana F, Champigny G, Waldmann R, de Weille JR, Heurteaux C, et al. (1997) The acid-sensitive ionic channel subunit ASIC and the mammalian degenerin MDEG form a heteromultimeric $\mathrm{H}+$-gated $\mathrm{Na}+$ channel with novel properties. J Biol Chem 272: 28819-28822.

18. Benson CJ, Xie J, Wemmie JA, Price MP, Henss JM, et al. (2002) Heteromultimers of DEG/ENaC subunits form $\mathrm{H}+$-gated channels in mouse sensory neurons. Proc Natl Acad Sci USA 99: 2338-2343.

19. Harding AM, Kusama N, Hattori T, Gautam M, Benson CJ (2014) ASIC2 subunits facilitate expression at the cell surface and confer regulation by PSD-95. PLoS One 9: e93797.

20. Hesselager M, Timmermann DB, Ahring PK (2004) pH Dependency and desensitization kinetics of heterologously expressed combinations of acid-sensing ion channel subunits. J Biol Chem 279: 11006-11015.

21. Kikuchi S, Ninomiya T, Kawamata T, Ogasawara N, Kojima T, et al. (2010) The acid-sensing ion channel 2 (ASIC2) of ciliated cells in the developing rat nasal septum. Arch Histol Cytol 73: 81-89.

22. Kikuchi S, Ninomiya T, Kawamata T, Tatsumi H (2008) Expression of ASIC2 in ciliated cells and stereociliated cells. Cell Tissue Res 333: 217-224.

23. Viña E, Parisi V, Abbate F, Cabo R, Guerrera MC, et al. (2015) Acidsensing ion channel 2 (ASIC2) is selectively localized in the cilia of the non-sensory olfactory epithelium of adult zebrafish. Histochem Cell Biol 143: 59-68.
24. Kawamata T, Ninomiya T, Toriyabe M, Yamamoto J, Niiyama Y, et al. (2006) Immunohistochemical analysis of acid-sensing ion channel 2 expression in rat dorsal root ganglion and effects of axotomy. Neuroscience 143: 175-187.

25. Price MP, Gong H, Parsons MG, Kundert JR, Reznikov LR, et al. (2014) Localization and behaviors in null mice suggest that ASIC1 and ASIC2 modulate responses to aversive stimuli. Genes Brain Behav 13: 179-194.

26. Sakka L, Coll G, Chazal J (2011) Anatomy and physiology of cerebrospinal fluid. Eur Ann Otorhinolaryngol Head Neck Dis 128: 309-316.

27. Del Bigio MR (2010) Ependymal cells: biology and pathology. Acta Neuropathol 119: 55-73.

28. Wodarczyk C, Rowe I, Chiaravalli M, Pema M, Qian F, et al. (2009) A novel mouse model reveals that polycystin-1 deficiency in ependyma and choroid plexus results in dysfunctional cilia and hydrocephalus. PLoS One 4: e7137.

29. Ibañez-Tallon I, Pagenstecher A, Fliegauf M, Olbrich H, Kispert A, et al. (2004) Dysfunction of axonemal dynein heavy chain Mdnah5 inhibits ependymal flow and reveals a novel mechanism for hydrocephalus formation. Hum Mol Genet 13: 2133-2141.

30. Prochnow N, Dermietzel R (2008) Connexons and cell adhesion: a romantic phase. Histochem Cell Biol 130: 71-77.

31. Conductier G, Brau F, Viola A, Langlet F, Ramkumar N, et al. (2013) Melanin-concentrating hormone regulates beat frequency of ependymal cilia and ventricular volume. Nat Neurosci 16: 845-847.

32. Zha XM, Costa V, Harding AM, Reznikov L, Benson CJ, et al. (2009) ASIC2 subunits target acid-sensing ion channels to the synapse via an association with PSD-95. J Neurosci 29: 8438-8446.

33. Price MP, Lewin GR, McIlwrath SL, Cheng C, Xie J, et al. (2000) The mammalian sodium channel $\mathrm{BNC1}$ is required for normal touch sensation. Nature 407: 1007-1011.

34. Lingueglia E (2007) Acid-sensing ion channels in sensory perception. J Biol Chem 282: 17325-17329.

35. Drew LJ, Rohrer DK, Price MP, Blaver KE, Cockayne DA, et al. (2004) Acid-sensing ion channels ASIC2 and ASIC3 do not contribute to mechanically activated currents in mammalian sensory neurons. J Physiol 556: 691-710.

36. Kang S, Jang JH, Price MP, Gautam M, Benson CJ, et al. (2012) Simultaneous disruption of mouse ASIC1a, ASIC2 and ASIC3 genes enhances cutaneous mechanosensitivity. PLoS One 7: e35225.

37. Roza C, Puel JL, Kress M, Baron A, Diochot S, et al. (2004) Knockout of the ASIC2 channel in mice does not impair cutaneous mechanosensation, visceral mechanonociception and hearing. J Physiol 558: 659-669.

38. Bloodgood RA (2010) Sensory reception is an attribute of both primary cilia and motile cilia. J Cell Sci 123: 505-509.

39. Jain R, Javidan-Nejad C, Alexander-Brett J, Horani A, Cabellon MC, et al. (2012) Sensory functions of motile cilia and implication for bronchiectasis, Front Biosci (Schol Ed) 4: 1088-1098. 